Review

\title{
An Advanced Electron Spin Resonance (ESR) Spin-Trapping and LC/(ESR)/MS Technique for the Study of Lipid Peroxidation
}

\author{
Yi Xu, Yan Gu and Steven Y. Qian * \\ Department of Pharmaceutical Sciences, College of Pharmacy, Nursing and Allied Sciences, \\ North Dakota State University, Fargo, ND 58108, USA; E-Mails: yi.xu@ndsu.edu (Y.X.); \\ anna.gu@my.ndsu.edu (Y.G.) \\ * Authors to whom correspondence should be addressed; E-Mail: steven.qian@ndsu.edu; \\ Tel.: +1-701-231-8511; Fax: +1-701-231-8333.
}

Received: 29 September 2012; in revised form: 1 November 2012 / Accepted: 2 November 2012 / Published: 12 November 2012

\begin{abstract}
There are two types of nutritionally important polyunsaturated fatty acids (PUFAs), namely $\omega-6 \mathrm{~s}$ and $\omega-3 \mathrm{~s}$. PUFAs and their metabolites generated from lipid peroxidation via cyclooxygenase (COX) and lipoxygenase (LOX) are believed to be involved in a variety of physiological and pathological processes in the human body. Both COX- and LOX-catalyzed PUFA peroxidation are complex events that generate a series of radicals, which may then bind proteins, target DNA/RNA, and lead to a number of biological changes. However, due to the lack of an appropriate method, it was not possible until recently to identify the short-lived PUFA-derived radicals in COX-/LOX-catalyzed peroxidation. Failure to characterize free radicals during peroxidation has greatly restricted our knowledge about COX/LOX biology in human health. Here we review the development and refinement of combined ESR spin trapping and LC/ESR/MS to characterize PUFA-derived radicals formed from in vitro (cell-free) peroxidation. We also present the most recent approach for studying peroxidation in cells which allows us to directly assess the potential bioactivity of PUFA-derived free radicals. This advanced technique has resulted in a major breakthrough in radical structural characterization, as well as assessment of free radical-associated cell growth response, thereby greatly improving our knowledge of PUFAs, COX-/LOX-catalyzed lipid peroxidation, and their related biological consequences.
\end{abstract}


Keywords: COX- and LOX-catalyzed lipid peroxidation; ESR spin-trapping; free radicals from cellular peroxidation; human colon cancer HCA7 colony 29 cells; LC/ESR and LC/MS combined technique

Abbreviations: AA, arachidonic acid; COX, cyclooxygenase; DGLA, dihomo- $\gamma$-linolenic acid; DHA, docosahexaenoic acid; DMPO, 5,5-dimethyl-1-pyrroline $N$-oxide; DPA, docosapentaenoic acid; EIC, extracted ion current; EPA, eicosapentaenoic acid; ESR, electron spin resonance; HOAc, acetic acid; HPLC (LC), high performance liquid chromatography; LA, linoleic acid; LNA, linolenic acid; LOX, lipoxygenase; MS, mass spectrometry; MNP, 2-methyl-2-nitrosopropane; NMR, nuclear magnetic resonance; PBN, $\alpha$-phenyl-tert-butylnitrone; POBN, $\alpha$-[4-pyridyl-1-oxide]- $N$-tert-butylnitrone; PG, prostaglandin; PUFAs, polyunsaturated fatty acids; THF, tetrahydrofuran; TMPO, 3,3,5,5-tetramethylpyrroline- $N$-oxide; $t_{\mathrm{R}}$, retention time.

\section{Introduction}

Polyunsaturated fatty acids (PUFAs) are one family of the most important components of cell membranes in living systems. Depending on the location of the first carbon-carbon double bond from the alkyl end of their backbones, two classes of PUFAs have been distinguished, namely $\omega-6 \mathrm{~s}$, e.g., dihomo- $\gamma$-linolenic acid (DGLA), linoleic acid (LA), and arachidonic acid (AA); and $\omega-3 \mathrm{~s}$, e.g., eicosapentaenoic acid (EPA), docospentaenoic acid (DPA), and docosahexenoic acid (DHA) [1-3]. Upon uptake from the diet or upon release from a cell membrane, the PUFAs will undergo enzyme-catalyzed lipid peroxidation, a well-known free radical-mediated metabolic process:

$$
\begin{array}{ll}
\mathrm{LH}^{+} \mathrm{X}^{\bullet} \rightarrow \mathrm{L}^{\bullet}+\mathrm{XH} & \text { (Initiation) } \\
\mathrm{L}^{\bullet}+\mathrm{O}_{2} \rightarrow \mathrm{LOO}^{\bullet} & \text { (Propagation) } \\
\mathrm{LOO}^{\bullet}+\mathrm{LH} \rightarrow \mathrm{LOOH}+\mathrm{L}^{\bullet} & \text { (Propagation) } \\
\mathrm{L}^{\bullet}+\mathrm{L}^{\bullet} \rightarrow \text { nonradical products } & \text { (Termination) } \\
\mathrm{L}^{\bullet}+\mathrm{LOO}^{\cdot} \rightarrow \text { nonradical products } & \text { (Termination) }
\end{array}
$$

The C-H bond at the bis-allylic methylene position of the PUFA is most vulnerable to oxidation due to its low dissociation energy ( $75 \mathrm{kcal} / \mathrm{mol})$ compared to a typical alkyl C-H bond $(\sim 101 \mathrm{kcal} / \mathrm{mol})[4,5]$. After $\mathrm{H}$ abstraction at this position by oxidants $\left(\mathrm{X}^{*}\right)$ like hydroxyl radical and activated species in oxidizing enzymes, a lipid molecule ( $\mathrm{LH}$ ) will be converted into a carbon-centered lipid radical ( $\mathrm{L}^{\circ}$ ). The $\mathrm{L}^{\cdot}$ will then react with $\mathrm{O}_{2}$ to form peroxyl radical $\left(\mathrm{LOO}^{\circ}\right)$, which can further attack other lipid molecules during the propagation process. In addition, the $\mathrm{LOO}^{\circ}$ can also be converted into other types of free radicals through Fenton-type reactions and $\beta$-scission [4,6-9].

Cyclooxygenase (COX) and lipoxygenase (LOX) are two families of lipid-peroxidizing enzymes which are responsible for the PUFA peroxidation pathway [10-20]. Their oxidase activities catalyze the conversion of PUFAs into various lipid derivatives (e.g., prostaglandins, thromboxanes), thus triggering a series of biochemical events which may lead to inflammatory disorders and various cancers [21-26]. 
The importance of PUFAs, as well as their metabolites, in maintaining hemostasis has attracted great research interest [27-36], and the investigation of the various radical intermediates generated during lipid peroxidation seems promising and may provide us with new insight into this area. However, there has been no appropriate methodology until the last few years for the detection and characterization of radical species due to their high reactivity and extremely short lifetimes. Failure to identify and quantify free radicals in biological systems has restricted our understanding of the biological implications of PUFAs in many diseases, especially in the inflammatory disorders and cancer.

In this paper, we review the development and refinement of a combined Electron Spin Resonance (ESR) spin-trapping and LC/ESR/MS technique for radical detection and characterization. We will focus mainly on its applications in a number of recent studies regarding COX/LOX-catalyzed lipid peroxidation. In addition, we will also present some recent data from an updated ESR spin trapping-LC/MS protocol, in which both the formation of free radicals from cellular lipid peroxidation and the radicals' bioactivities under normal cellular growth conditions could be assessed at the same time and under the same experimental settings. All of these promising efforts towards the development, refinement and application of this combined technique will definitely improve our knowledge of PUFA-related bioactivities and COX/LOX-related cancer biology.

\section{History of the ESR Spin-Trapping Technique}

Electron Spin Resonance (ESR), also known as Electron Paramagnetic Resonance (EPR), is the conventional technique capable of directly detecting radical species. It has a principle similar to Nuclear Magnetic Resonance (NMR), but responds to the transition of electron spins between energy levels in unpaired electron-containing materials. This characteristic offers ESR a unique specificity for the measurement of free radicals. However, the high reactivity and short lifetimes of free radicals usually make them very unstable, particularly in biological systems, thus rendering them undetectable by ESR. To overcome this shortcoming, a spin-trapping technique came out in the early 1970s, in which the primary free radicals are allowed to react with spin-trapping agents (nitrone or nitroso compounds) to form a more stable radical spin-trapping adduct prior to direct ESR detection [37-40]. The application of the coupled spin-trapping ESR technique seems promising for the investigation of almost all types of radical species, as long as one can find a suitable spin trap agent for the particular radical of interest. As a consequence, many spin trap agents have been developed, including $\alpha$-phenyl-tert-butylnitrone (PBN), 2-methyl-2-nitrosopropane (MNP), $\alpha$-[4-pyridyl 1-oxide]- $N$-tert-butyl nitrone (POBN), 3,3,5,5-tetramethylpyrroline- $N$-oxide (TMPO), nitrosodurene and 5,5-dimethyl-1pyrroline $N$-oxide (DMPO) [41-53].

Among all of the spin trap agents, due to its good spin-trapping ability and satisfactory solubility in biological media, POBN has been widely used to detect PUFA-derived free radicals formed from in vitro and in vivo lipid peroxidation (Reaction 1) [5,9,54-59]:

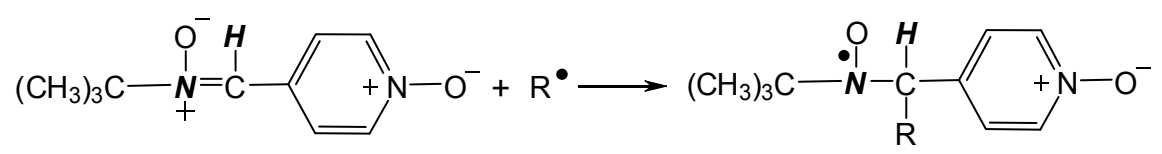

(Reaction 1)

POBN + Free Radical $\rightarrow$ POBN/Radical Adduct 
Although the appearance of the spin-trapping ESR technique provides us an easier way to work with radicals, the unambiguous structural assignment of radical species from ESR spectra still remains a problem. For instance, the POBN adducts of various radicals usually give six-line ESR spectrum with very similar hyperfine coupling constants: $\alpha^{\mathrm{N}} \approx 14.4 \sim 16.1 \mathrm{G}$ and $\alpha^{\mathrm{H}} \approx 2.2 \sim 2.8 \mathrm{G}$ (Figure 1) [9,60], because the splitting of the ESR signal mainly originates from the $\mathrm{N}$ and $\mathrm{H}$ atoms in the POBN molecule instead of from atoms in the different primary radical species. This feature makes it impossible to structurally distinguish each individual free radical trapped and generated from complex biological systems where more than one radical species are concurrently formed. Morever, unlike other comprehensive analytical techniques such as NMR and MS spectrometry, the ESR itself can hardly be viewed as a potent method for molecule identification because its unique parameters, such as hyperfine coupling constant and g value, provide structural information with insufficient specificity.

Figure 1. A typical ESR spectrum generated from a POBN radical adduct. The hyperfine coupling constants are $\alpha^{\mathrm{N}} \approx 14.4 \sim 16.1 \mathrm{G}$ and $\alpha^{\mathrm{H}} \approx 2.2 \sim 2.8 \mathrm{G}[9,60]$.

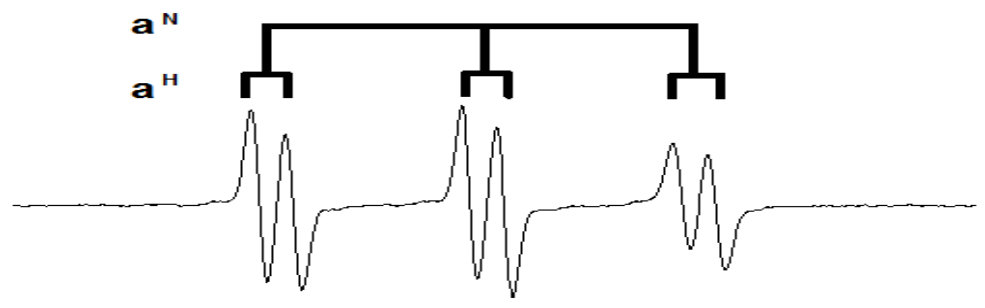

\section{Development of the Combined ESR Spin-Trapping and LC/ESR/MS Technique}

In order to overcome the above limitations, a combination system employing ESR and HPLC as well as $\mathrm{MS}$ and/or tandem MS $\left(\mathrm{MS}^{2}\right)$ has been developed to characterize individual radical species generated from PUFA peroxidation (Scheme 1). Briefly, spin trap adducts of radicals with different structures are first separated by a HPLC column according to their distinct chromatographic behavior, followed by ESR monitoring for radical confirmation and MS detection for structural identification. Note that in the online LC/ESR system, a time scan mode is used with the magnetic field fixed at the top of one line of the POBN adduct spectrum instead of running an entire magnetic field scan in offline ESR detection. With this practice, a series of absorption peaks matched to HPLC retention times can be observed, and each peak represents a structurally distinct free radical trapped by POBN.

The early effort in the development of this technique came from Iwahashi et al. in the late 1980's [61,62]. The combined LC/ESR and LC/MS technique was employed in that work for the characterization of free radicals produced from PUFA peroxidation, epoxidation and $\beta$-scission. However, due to the unavailability of more advanced analytical techniques, some problems emerged in those early developments of the combined technique. For instance, the UV chromatogram of the system had never been reported due to poor chromatography resolution; the semipreparative LC column instead of the analytical one was employed, thus very large amounts of samples were required for these experiments, which is not feasible for biological systems; the ESR-active fractions were not detected as the corresponding $\mathrm{m} / \mathrm{z}$ ions, but instead, the ions of the reduced forms of spin adducts were assigned based on their ESR-active peaks; some radical adducts, particularly those with a $-\mathrm{COOH}$ moiety ( $\sim \mathrm{pKa} 5.0$ ), could have very poor retention behavior due to the $\mathrm{pH}$ range (5-6) of the mobile 
phase (ammonium acetate) used for chromatographic separation; and a serious ESR-tuning problem appeared due to poor chromatograph resolution and low sensitivity arising from interface issues between the LC and ESR. This tuning problem often created artificial online ESR peaks during LC/ESR detection, thus raising the question of the method's reliability.

Scheme 1. HPLC/ESR/MS combination for free radical detection and characterization. Spin-trapped free radicals with different structures are separated by an HPLC column according to their distinct chromatographic behavior, followed by ESR monitoring for radical confirmation and MS detection for structural identification.

\section{Sample Inj.}

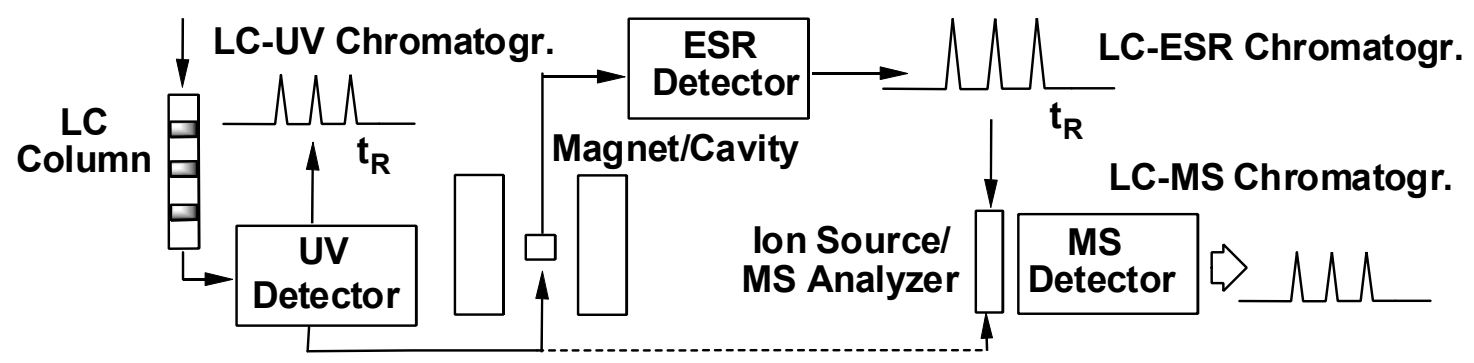

Liquid Chromatography Electron Spin Resonance Mass Spectrometry

Benefiting from great improvements in analytical technology, Qian et al. made a breakthrough in refining the LC/ESR and LC/MS methods to characterize PUFA-derived free radicals in many biological systems in the early 2000s [63-65]. The interface issues between online systems were tackled, and most problems encountered in previous developments have been successfully overcome: (1) replacing the classic ODS column (filled with a packing of octadecylsilyl groups chemically bonded to a silica gel) with a rapid resolution Eclipse column (extra dense bonding, high purity silica, and double endcapping) to achieve a better chromatographic resolution and sensitivity, allowing experiments to be conducted with analytic sampling and performance; (2) applying soft MS ionization and optimizing chromatographic separation to allow all ESR-active peaks to be detected as their corresponding $\mathrm{m} / \mathrm{z}$ ions; (3) adding $1.0 \%-0.01 \%$ acetic acid (HOAc) to the mobile phase to maintain a weakly acidic $\mathrm{pH}$ to improve the retention behavior of all types of POBN adducts; and (4) adding a very small amount of tetrahydrofuran (THF) to the mobile phase to improve LC resolution. Besides, THF can also stabilize ESR tuning during LC/ESR measurements, perhaps attributable to its low dielectric constant. However, due to its corrosiveness, THF was not used as a mobile phase component in later combination LC/ESR and LC/MS systems [42,66-71].

The combination of spin trapping and LC/ESR/MS as refined via Qian et al. not only optimizes the method's sensitivity and resolution, but also greatly improves the reliability of radical identification. Thus, it became a potent tool for later study on radical-mediated lipid peroxidation and its association with PUFA's bioactivities. In fact, with the refined combined technique, almost all of the carbon-centered radical adducts formed from LOX catalyzed PUFA peroxidation (including both $\omega-6 \mathrm{~s}$ and $\omega-3 \mathrm{~s}$ ) have been detected, structurally characterized and quantified (Scheme 2) [64-68]. These studies suggest that there is a PUFA type-dependent radical formation pattern in LOX-catalyzed lipid peroxidation: the peroxidation of $\omega-6$ PUFAs (except DGLA) tend to produce one major radical 
product, while $\omega-3$ PUFA peroxidation usually gives multiple radical metabolites. In addition, a change in the reaction $\mathrm{pH}$ was found to not only influence the total radical formation but also alter the preferred site of oxygenation in LOX-catalyzed PUFA peroxidation [68]. These PUFA type- and $\mathrm{pH}$-dependent alterations of radical formation and oxygenation pattern may have significant implications and provide a basis for further investigations of fatty acids in cancer biology, particularly those peculiar to the acidic tumor environment $(\mathrm{pH}$ 6.5) compared to the normal physiological environment ( $\mathrm{pH}$ 7.4).

Scheme 2. PUFA type-dependent free radical formation patterns of LOX-catalyzed lipid peroxidation. All of the listed free radical metabolites have been characterized in previous ESR spin-trapping and LC/ESR/MS studies [64-68]. Unlike the formation of one major radical product observed in LOX peroxidation of $\omega-6$ PUFAs, LOX-catalyzed peroxidation of all $\omega-3$ PUFAs along with DGLA (an exceptional $\omega-6$ ) tended to produce multiple radical metabolites. Note that a similar metabolism pattern and the same $\mathrm{pH}$-dependent oxygenation were observed in LOX-catalyzed DGLA $(\omega-6)$ peroxidation as in LOX-catalyzed $\omega$-3 PUFA peroxidation.

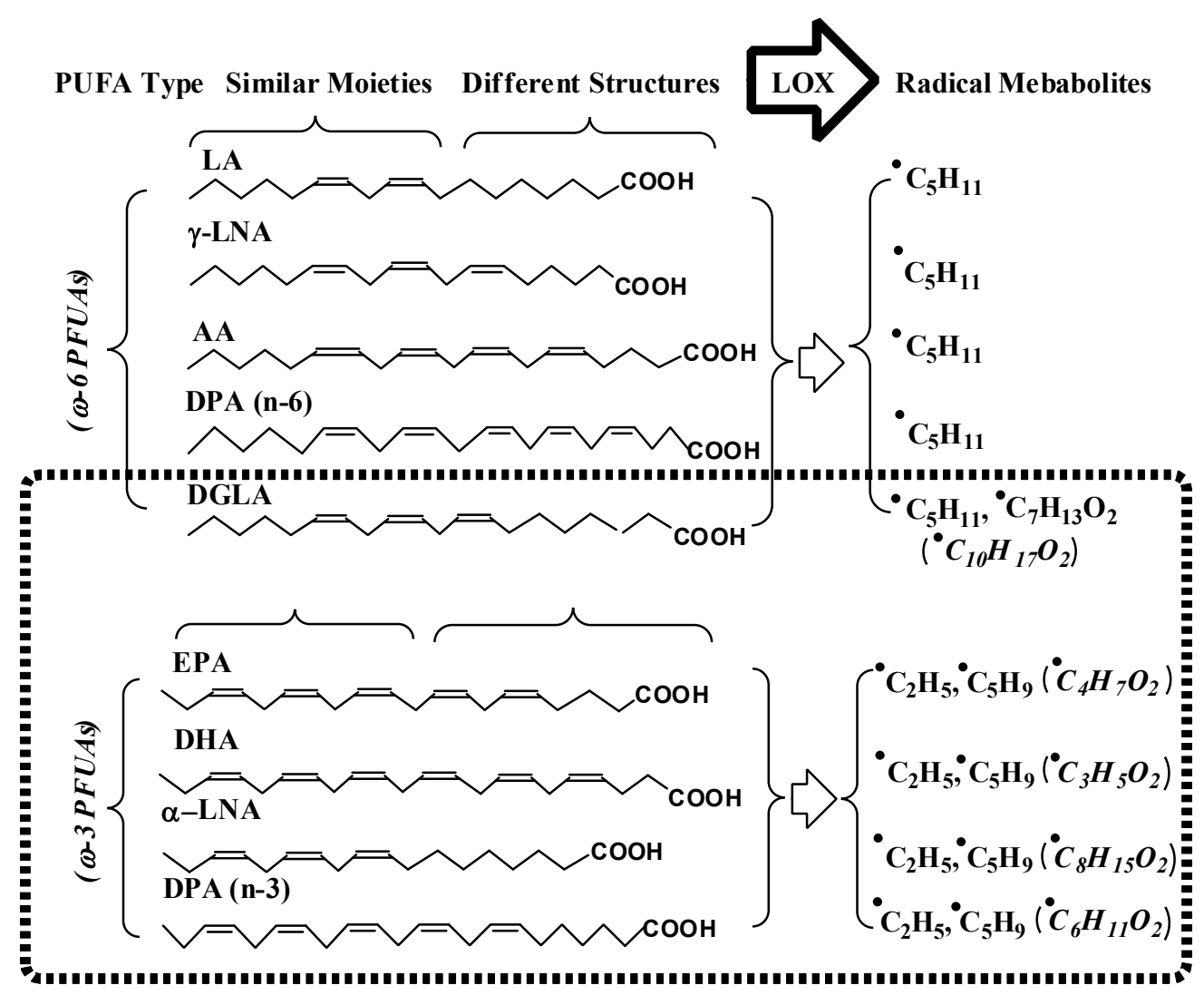

\section{Refined Combination of ESR Spin-Trapping and LC/MS Technique in Radical Characterization in in vitro (cell-free) COX-Catalyzed AA and DGLA Peroxidation}

AA (20:4) and its upstream fatty acid DGLA (20:3) are two major 20-carbon $\omega$-6 PUFAs in mammalian cells. During COX-catalyzed, free radical-mediated lipid peroxidation, DGLA and AA will be converted into 1-series Prostaglandins (PGs1) and 2-series Prostaglandin (PGs2), respectively, both of which are important signaling molecules implicated in a variety of physiological and 
pathological processes $[11,16,18,21,22,24,26]$. Interestingly, despite the structural similarity, AA and PGs2 are generally viewed as proinflammatory and protumorigenic factors, while DGLA and PGs1 may possess anticancer activity by virtue of suppressing oncogene expression and enhancing p53 activity [71-75]. Although this area has received a great deal of attention, the different radical-based mechanisms of DGLA peroxidation vs. AA peroxidation have never been clarified before due to the lack of appropriate methodology.

Using the combined ESR spin-trapping-LC/ESR and LC/MS technique, all the carbon centered free radicals formed in the COX/AA and COX/DGLA reaction systems were detected and structurally characterized in recent studies $[69,70]$. The results indicate that DGLA and AA share a common peroxidation mechanism and produce similar/identical radical products due to their structural similarity, while DGLA may also undergo a distinct reaction pathway to produce exclusive radical metabolites (Schemes 3,4).

Scheme 3. COX-catalyzed AA peroxidation pathway via C-15 oxygenation. Three major radical products (labeled with their corresponding molecular formulas) can be trapped by $\mathrm{POBN}$, thus are screened by $\mathrm{LC} / \mathrm{MS}$ as the radical adducts $\mathrm{POBN} /{ }^{\circ} \mathrm{C}_{14} \mathrm{H}_{21} \mathrm{O}_{4}$, POBN/ $/{ }^{\circ} \mathrm{C}_{6} \mathrm{H}_{13} \mathrm{O}$, and $\mathrm{POBN} /{ }^{\circ} \mathrm{C}_{5} \mathrm{H}_{11}$, with $\mathrm{m} / z$ of 448 , 296, and 266 , respectively. $\xi$ : Common radicals in COX/AA and COX/DGLA peroxidation. $\zeta$ : Exclusive radical in COX/AA peroxidation. All of the three major radical products can be observed in both the cell-free reactions and cellular experiments [71].

COXIAA peroxidation via $\mathrm{C}-15$ oxygenation
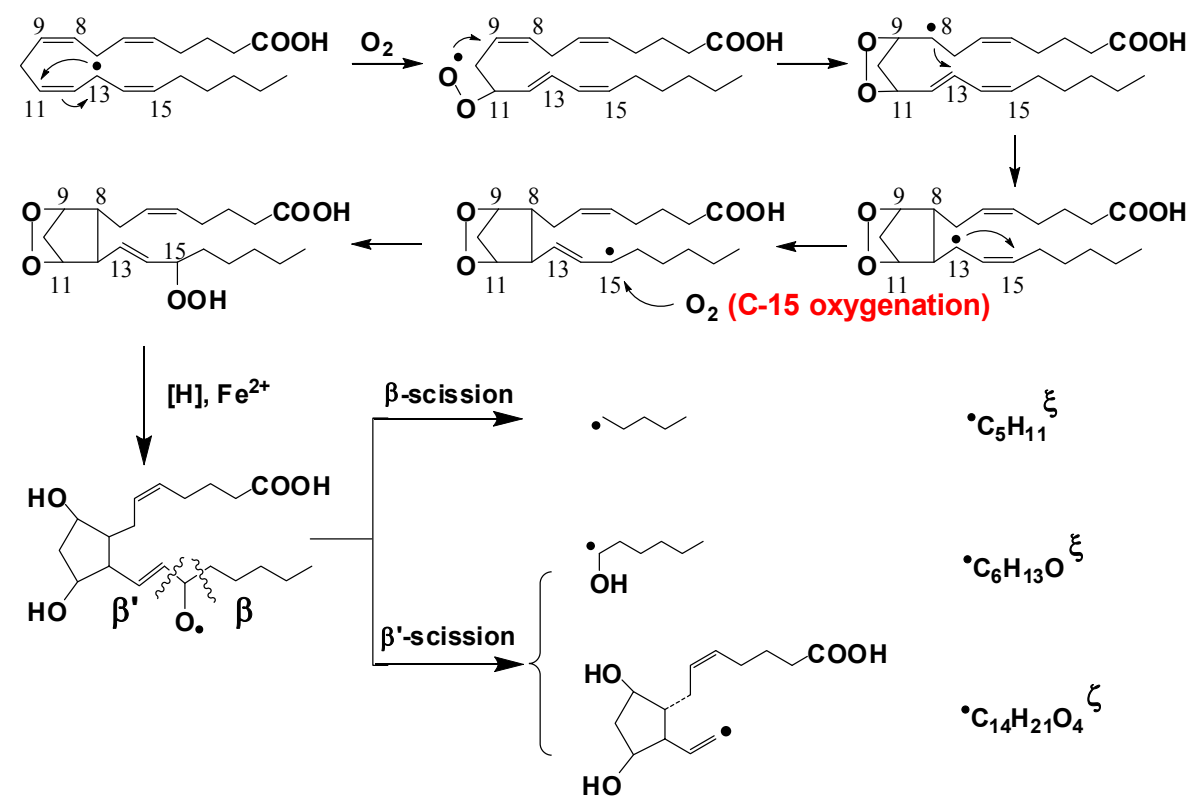

In the $\mathrm{COX} / \mathrm{AA}$ reaction system, an $\mathrm{H}$ atom is abstracted by $\mathrm{COX}$, and then the peroxidase activity catalyzes the introduction of one molecule of $\mathrm{O}_{2}$ onto $\mathrm{C}-11$ as the initiation step to form the C-9/C-11 endoperoxide, which is followed by $\mathrm{C}-8 / \mathrm{C}-12$ cyclization. Then the second $\mathrm{O}_{2}$ molecule is introduced on $\mathrm{C}-15$, a process called $\mathrm{C}-15$ oxygenation, to produce 2-series $\mathrm{PGs}$ including $\mathrm{PGG}_{2}, \mathrm{PGH}_{2}$ and $\mathrm{PGF}_{2}$. During this process, a total of four types of radicals have been characterized using the combined LC/ESR/MS technique, including: ${ }^{\circ} \mathrm{C}_{20} \mathrm{H}_{34} \mathrm{O}_{5}$ (not listed in Scheme 3) formed from the rearrangement 
of $\mathrm{PGF}_{2}$-type alkoxyl radicals; ${ }^{\circ} \mathrm{C}_{14} \mathrm{H}_{21} \mathrm{O}_{4}$, a novel double-bonded carbon-centered radical derived from $\mathrm{PGF}_{2}$ via a special $\beta$ '-scission; ${ }^{\circ} \mathrm{C}_{6} \mathrm{H}_{13} \mathrm{O}$, also derived from $\mathrm{PGF}_{2}$ via $\beta^{\prime}$-scission; and ${ }^{\circ} \mathrm{C}_{5} \mathrm{H}_{11}$, from $\beta$-scission of $\mathrm{PGF}_{2}$-type alkoxyl radicals (Scheme 3). After being spin trapped by POBN, all of these radical species were identified in LC/MS chromatography as ESR-active POBN/radical adducts: POBN/ $/ \mathrm{C}_{20} \mathrm{H}_{34} \mathrm{O}_{5}(m / z 548), \mathrm{POBN} /{ }^{\circ} \mathrm{C}_{14} \mathrm{H}_{21} \mathrm{O}_{4}\left(m / z\right.$ 448), $\mathrm{POBN} /{ }^{\circ} \mathrm{C}_{6} \mathrm{H}_{13} \mathrm{O}(m / z 296)$ and $\mathrm{POBN} /{ }^{\circ} \mathrm{C}_{5} \mathrm{H}_{11}$ $(m / z 266)$.

Scheme 4. Proposed reaction pathways for COX-catalyzed DGLA peroxidation. (A) COX/DGLA peroxidation via C-15 oxygenation; (B) COX/DGLA peroxidation via C-8 oxygenation (the first two steps are the same as with C-15 oxygenation). The radical products (labeled with the corresponding molecular formulas) can be trapped by $\mathrm{POBN}$, thus are screened by $\mathrm{LC} / \mathrm{MS}$ as the radical adducts $\mathrm{POBN} /{ }^{\circ} \mathrm{C}_{6} \mathrm{H}_{13} \mathrm{O}, \mathrm{POBN} /{ }^{\circ} \mathrm{C}_{5} \mathrm{H}_{11}$, POBN $/{ }^{\circ} \mathrm{C}_{8} \mathrm{H}_{15} \mathrm{O}_{3}$, and $\mathrm{POBN} /{ }^{\circ} \mathrm{C}_{7} \mathrm{H}_{13} \mathrm{O}_{2}$ with $\mathrm{m} / \mathrm{z}$ of $296,266,354,324$, respectively. $\xi$ : Radicals common to COX/AA and COX/DGLA peroxidation. $\zeta$ : Radical exclusive to COX/DGLA peroxidation. All of the major radical products can be observed in both cell-free reactions and cellular experiments [71].

\section{A. COX/DGLA peroxidation via C-15 oxygenation}

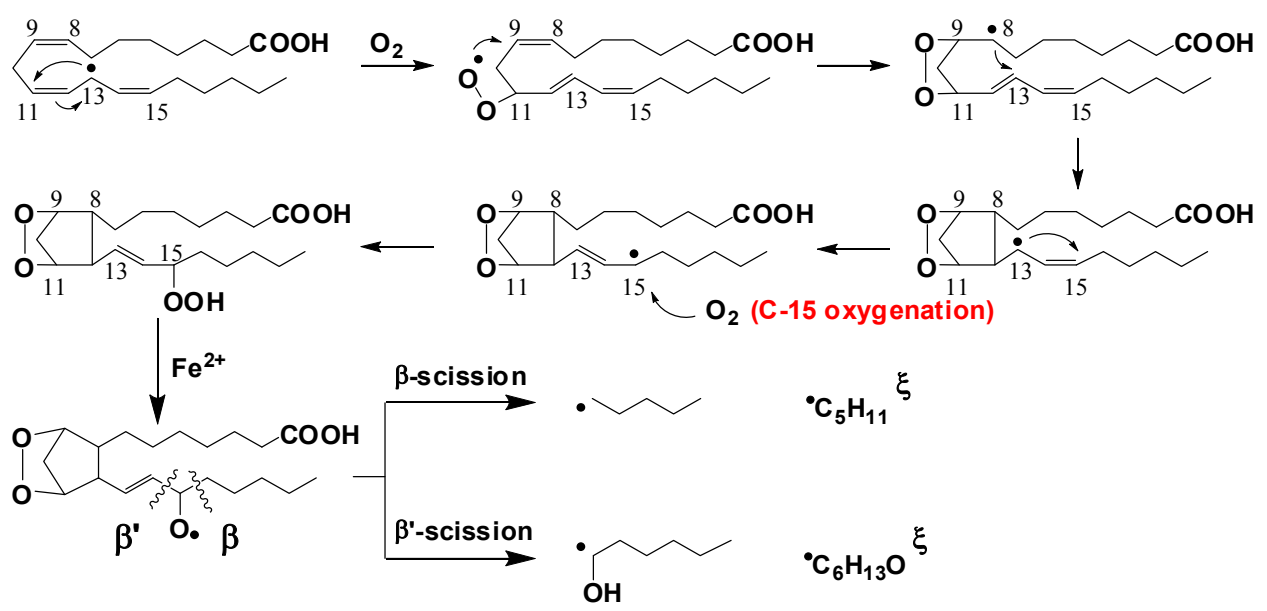

B. COX/DGLA peroxidation via C-8 oxygenation (exclusive)

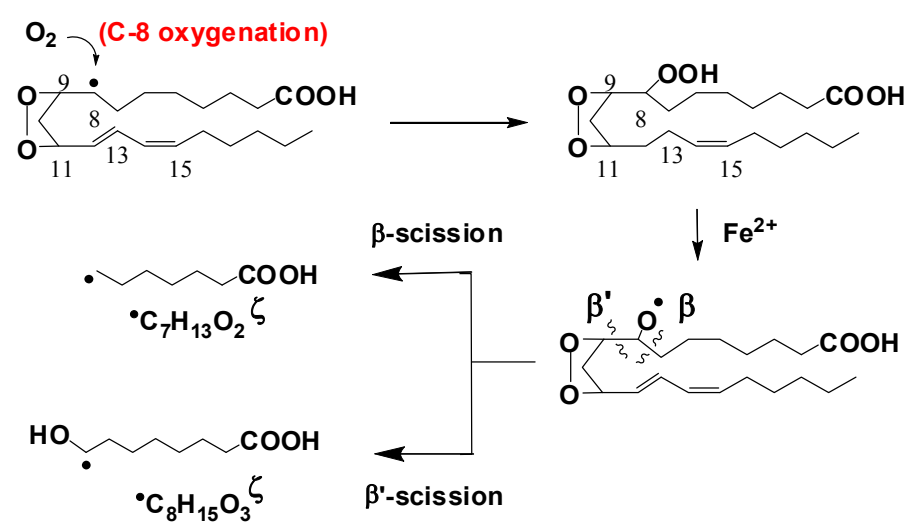

Similarly, C-15 oxygenation and $\beta$-scission as well as $\beta$ '-scission (Scheme 4A), were also observed in the COX/DGLA system to produce the radicals ${ }^{\circ} \mathrm{C}_{5} \mathrm{H}_{11}$ and ${ }^{\circ} \mathrm{C}_{6} \mathrm{H}_{13} \mathrm{O}$ in common with COX/AA 
pathway. However, no analog of the double-bonded carbon-centered radical ${ }^{\circ} \mathrm{C}_{14} \mathrm{H}_{21} \mathrm{O}_{4}$ was observed here, probably because the $\beta$ '-scission took place during $\mathrm{PGH}_{1}$ formation instead of $\mathrm{PGF}_{1}$ formation [69]. Interestingly, in addition to the common reaction pathway, a distinct C-8 oxygenation pathway was proposed for the COX/DGLA reaction. This proposed pathway was confirmed by the identification of two radicals produced exclusively in the COX/DGLA system, observed as their corresponding adduct forms: $\mathrm{POBN} /{ }^{\circ} \mathrm{C}_{7} \mathrm{H}_{13} \mathrm{O}_{2}\left(\mathrm{~m} / z\right.$ 324) and $\mathrm{POBN} /{ }^{\circ} \mathrm{C}_{8} \mathrm{H}_{15} \mathrm{O}_{3}(\mathrm{~m} / \mathrm{z}$ 354) (Scheme 4B). The successful detection and characterization of these novel and exclusive free radicals from COX-catalyzed AA and DGLA peroxidation (cell-free) is very exciting.

\section{Most Recent Update of ESR Spin-Trapping and LC/MS Protocol in Characterization of Free Radicals Formed from Cellular COX-Catalyzed AA and DGLA Peroxidation}

To extend the application of the combined ESR spin trapping-LC/(ESR)/MS technique into complicated biological systems, Gu et al. further refined the method in a cell culture experiment [71]. With the use of human colon cancer HCA-7 colony 29 cells (with a high COX expression) in the PBS solution along with a high dose of POBN $(50 \mathrm{mM})$ and PUFAs $(500 \mu \mathrm{M})$ in a 30 min incubation [71], both the common and the differing pathways, as well as the formation of various radical products in AA and DGLA peroxidation, were confirmed for the first time (Figure 2). However, this protocol obviously suffers from two critical shortcomings: (1) only a short incubation time can be achieved due to the replacement of the cell medium by PBS; (2) due to the complexity of cellular conditions, a high dose of PUFAs as well as POBN must be used for cell treatment to get a satisfactory LC/MS signal intensity, and this excess of POBN and PUFA supplement can lead to cell death within one hour. As a result, it seems impossible to use this protocol to test cell proliferation, apoptosis and cell cycle distribution, thereby impeding assessment of the association between radical production and the biological activities of PUFAs.

In order to overcome the problems encountered in previous practices, the most updated combined technique was subjected to further refinement to characterize lipid-derived radicals under normal cellular growth conditions. It was proposed, due to the cellular reducing environment, that the POBN/radical adduct in ESR-active form could be easily reduced to hydroxylamine (Scheme 5) [71]. The hydroxylamine is a more stable redox form of radical adduct that can accumulate after a long incubation time and is readily detected by LC/MS.

Therefore, instead of directly detecting the ESR-active radical adducts, we subjected their reduced hydroxylamine forms to the LC/MS screen to profile the radical production in lipid peroxidation under normal cellular growth conditions. To achieve this, we employed a mixed-mode anion exchange SPE cartridge to extract and condense the hydroxylamines by taking advantage of the charge of the pyridyl-oxide group of the reduced POBN adduct. In this case, the cells were allowed to grow in cell culture media supplemented with much less POBN $(20 \mathrm{mM})$ and PUFAs $(100 \mu \mathrm{M})$. At different time points up to $48 \mathrm{~h}$ during a long incubation time, the cells together with media were collected and subjected to solid phase extraction (SPE) for condensation, followed by LC/MS and LC/MS ${ }^{2}$ detection. 
Figure 2. LC/MS chromatogram (EIC) of radical adducts from cellular PUFA peroxidation. (A) radical adducts from cells treated with AA; and $(\mathbf{B})$ radical adducts from cells treated with DGLA. HCA-7 colony 29 cells were harvested and suspended in PBS. After being treated with high doses of POBN and PUFAs, the cells were incubated for 30 min. Then the reaction was stopped by mixing with ACN, and the supernatant was collected, centrifuged and condensed followed by LC/MS detection. In the COX/AA system, $m / z 548,448,296$, and 266 correspond to $\mathrm{POBN} /{ }^{\circ} \mathrm{C}_{20} \mathrm{H}_{34} \mathrm{O}_{5}, \mathrm{POBN} /{ }^{\circ} \mathrm{C}_{14} \mathrm{H}_{21} \mathrm{O}_{4}$, $\mathrm{POBN} /{ }^{\circ} \mathrm{C}_{6} \mathrm{H}_{13} \mathrm{O}$ and $\mathrm{POBN} /{ }^{\circ} \mathrm{C}_{5} \mathrm{H}_{11}$, respectively, which all come from $\mathrm{C}-15$ oxygenation. In the COX/DGLA system, m/z 296 and 266 correspond to the common radical adducts $\mathrm{POBN} /{ }^{\circ} \mathrm{C}_{6} \mathrm{H}_{13} \mathrm{O}$ and $\mathrm{POBN} /{ }^{\circ} \mathrm{C}_{5} \mathrm{H}_{11}$ from $\mathrm{C}-15$ oxygenation, while $\mathrm{m} / \mathrm{z} 354$ and 324 correspond to $\mathrm{POBN} / \mathrm{C}_{8} \mathrm{H}_{15} \mathrm{O}_{3}$ and $\mathrm{POBN} /{ }^{\circ} \mathrm{C}_{7} \mathrm{H}_{13} \mathrm{O}_{2}$, two exclusive radical adducts from $\mathrm{C}-8$ oxygenation in the COX/DGLA system.

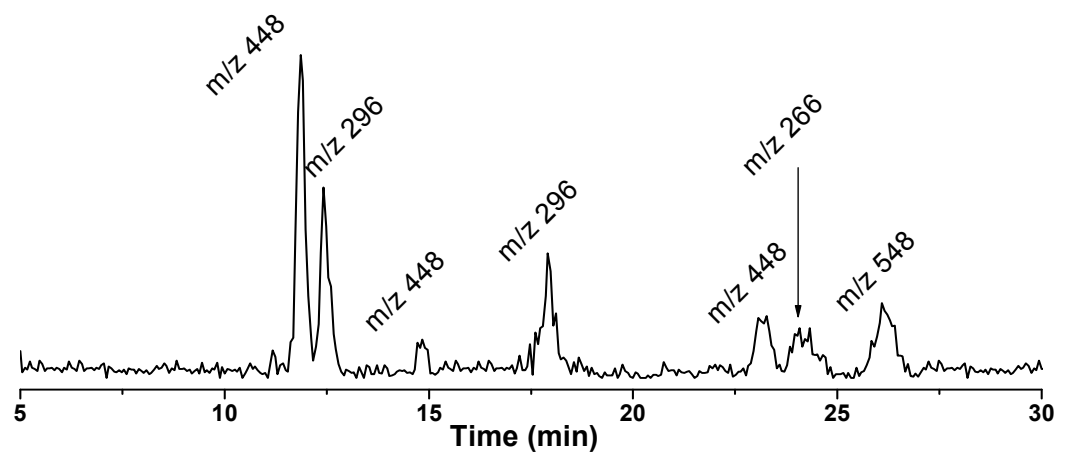

(A)

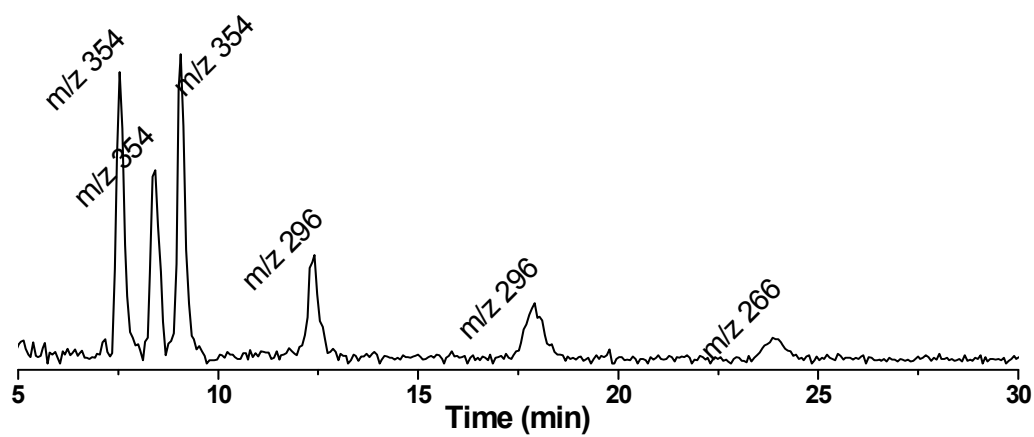

(B)

Scheme 5. Refined ESR spin-trapping, SPE, LC/MS combined technique for characterization of radical adducts in reduced forms under normal cellular growth conditions. After a long incubation time, only the hydroxylamine of the radical adduct will accumulate, thus giving an LC/MS signal after SPE condensation.

LC/MS Detection
POBN/Adduct (Protonated, $\mathrm{m} / \mathbf{z} \mathrm{M}+1$ )<smiles>[R]C(c1cc[n+]([O-])cc1)N([O-])C(C)(C)C</smiles>

Hydroxylamine (Protonated, $\mathrm{m} / \mathrm{z} \mathrm{M}+2$ )

LC/MS Detection

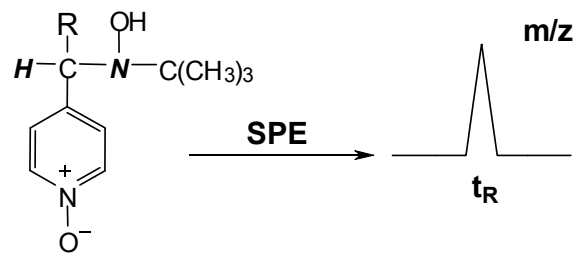


As expected, the radical adducts in their reduced forms (hydroxylamines), but not the ESR-active forms, accumulated and were observed under these conditions. For instance, in the COX/AA system, the reduced forms of the POBN/ $\mathrm{C}_{6} \mathrm{H}_{13} \mathrm{O}$ and $\mathrm{POBN} /{ }^{\circ} \mathrm{C}_{14} \mathrm{H}_{21} \mathrm{O}_{4}$ adducts were observed with the corresponding $\mathrm{m} / \mathrm{z}$ values of 297 and 449, respectively, instead of their ESR-active forms $(\mathrm{m} / \mathrm{z} 296$ and $m / z 448$, respectively). Likewise, in the COX/DGLA system, the reduced forms of $\mathrm{POBN} /{ }^{\circ} \mathrm{C}_{6} \mathrm{H}_{13} \mathrm{O}$, POBN/ $/ \mathrm{C}_{7} \mathrm{H}_{13} \mathrm{O}_{2}$ and POBN/ ${ }^{\circ} \mathrm{C}_{8} \mathrm{H}_{15} \mathrm{O}_{3}$ were observed up to $48 \mathrm{~h}$ with their corresponding $\mathrm{m} / \mathrm{z}$ values of 297, 325 and 355, respectively (Figures 3,4). Dual spin-trapping experiments and $\mathrm{MS}^{2}$ detection were also conducted to further confirm the hydroxylamines as radical derivatives [71].

\section{Direct Assessment of the Association between Radical Production and Cell Growth Response}

With the most recently refined protocol, the radical products in COX/PUFA peroxidation were profiled under normal cell growth conditions, and their association with cell proliferation was assessed [71]. Here, the reduced form of the common radical adduct $\mathrm{POBN} /{ }^{\circ} \mathrm{C}_{6} \mathrm{H}_{13} \mathrm{O}(\mathrm{m} / \mathrm{z} 297)$ was observed in both the COX/AA and COX/DGLA systems, and its production reached a peak at $12 \mathrm{~h}$ and started to decrease over the next two days. The hydroxylamine of the exclusive adduct in the COX/AA system, $\mathrm{POBN} /{ }^{\circ} \mathrm{C}_{14} \mathrm{H}_{21} \mathrm{O}_{4}(\mathrm{~m} / z$ 449), was not observed until the $8 \mathrm{~h}$-time point and reached a peak at 12 h. Similarly, the hydroxylamines of the two exclusive adducts in the COX/DGLA system, POBN/ ${ }^{\circ} \mathrm{C}_{7} \mathrm{H}_{13} \mathrm{O}_{2}(m / z ~ 325)$ and $\mathrm{POBN} /{ }^{\circ} \mathrm{C}_{8} \mathrm{H}_{15} \mathrm{O}_{3}(\mathrm{~m} / z$ 355), also started to appear at $8 \mathrm{~h}$ and reached a peak at $24 \mathrm{~h}$ (Figure 4).

Interestingly, because the DGLA can be converted into AA by $\Delta-5$ desaturase present in cells, the exclusive AA-derived hydroxylamine ( $\mathrm{POBN} / \mathrm{C}_{14} \mathrm{H}_{21} \mathrm{O}_{4}, \mathrm{~m} / z$ 449) was also observed in the COX/DGLA system, although no AA was introduced (Figures 3B,4). When CP-24879, an inhibitor of $\Delta-5$ desaturase, was introduced into the COX/DGLA system, the exclusive AA-derived hydroxylamine was barely detected. The formation of the $m / z 449$ product seems a very likely response to cancer cell growth. Recent data has also shown that DGLA treatment was associated with sustained $\mathrm{G}_{2}$ phase cell cycle arrest compared to control after 8 h-incubation [71]. However, after one day of treatment, there was almost no difference in cell growth and cell cycle distribution between AA and DGLA treatments. Nevertheless, after one day of incubation, the addition of DGLA, together with CP-24879, resulted in sustained $\mathrm{G}_{2}$ phase cell cycle arrest and inhibited cell proliferation, e.g., a significant difference from AA or DGLA treatment alone (Table 1).

Table 1. Effect of PUFAs on cellular growth response.

\begin{tabular}{|c|c|c|c|}
\hline \multirow{3}{*}{$\begin{array}{l}\text { Cells (HCA-7 Colony 29) } \\
\text { Cultured with }\end{array}$} & \multicolumn{2}{|c|}{ Cell $G_{2}$ Arrest } & Cell Proliferation \\
\hline & \multicolumn{2}{|c|}{$\%$ in $\mathrm{G}_{2}$ Phase } & $\%$ Viability \\
\hline & $8 \mathrm{~h}$ & $24 \mathrm{~h}$ & $48 \mathrm{~h}$ \\
\hline Control $^{\mathrm{a}}$ & $29.7 \pm 2.3$ & $28.6 \pm 1.6$ & 100 \\
\hline $\mathrm{AA}(100 \mu \mathrm{M})$ & $27.9 \pm 1.9$ & $30.5 \pm 2.1$ & $112.1 \pm 3.9$ \\
\hline $\operatorname{DGLA}(100 \mu \mathrm{M})$ & $41.3^{b} \pm 2.5$ & $31.4 \pm 2.0$ & $109.1 \pm 5.7$ \\
\hline DGLA with $5.0 \mu \mathrm{M}$ of $\mathrm{CP}$ & $42.4^{\mathrm{b}} \pm 1.8$ & $35.3^{b} \pm 0.9$ & $98.3^{\mathrm{c}} \pm 5.0$ \\
\hline
\end{tabular}

Cell cycle analysis (via PI staining) and cell proliferation assays (via MTS) were conducted using HCA-7 colony 29 cells treated with AA, DGLA and DGLA in combination with CP-24879 ( $\Delta-5$ desaturase inhibitor). a: \% cell viability was compared with the control group; b: significantly different $(p<0.01) v$. control; c: significantly different $v s$. treatment of AA and DGLA. 
Figure 3. $\mathrm{LC} / \mathrm{MS}$ and $\mathrm{LC} / \mathrm{MS}^{2}$ detection of hydroxylamines from cellular PUFA peroxidation. (A) EIC of hydroxylamines in COX/AA cellular system, $8 \mathrm{~h}$; (B) EIC of hydroxylamines in COX/DGLA cellular system, $12 \mathrm{~h}$; (C) $\mathrm{MS}^{2}$ spectrum of hydroxylamines of $\mathrm{m} / \mathrm{z} 297$; (D) $\mathrm{MS}^{2}$ spectrum of hydroxylamines of $\mathrm{m} / \mathrm{z} 325$; (E) $\mathrm{MS}^{2}$ spectrum of hydroxylamines of $\mathrm{m} / \mathrm{z} 449$; and F) $\mathrm{MS}^{2}$ spectrum of hydroxylamines of $\mathrm{m} / \mathrm{z}$ 355. Fragment a: $\mathrm{M}-\left[\mathrm{C}\left(\mathrm{CH}_{3}\right)_{3}\right]$; b: $\mathrm{M}-\left[\mathrm{HO}-\mathrm{N}-\mathrm{C}\left(\mathrm{CH}_{3}\right)_{3}\right]$; c: $\mathrm{M}-[\mathrm{R}]$; d: $\mathrm{M}-[\mathrm{POBN}]$. Note: in Figure 1B, the marked peak of $m / z 449$ in the COX/DGLA system comes from the conversion of DGLA to AA.

\section{A. Radicals from COX/AA system}

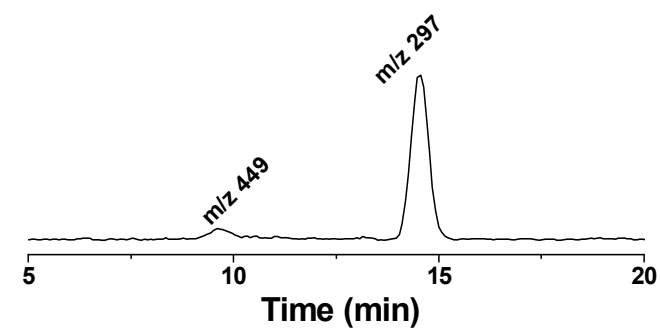

C. $L C / M S^{2}$ of $\mathbf{m} / \mathbf{z} 297$

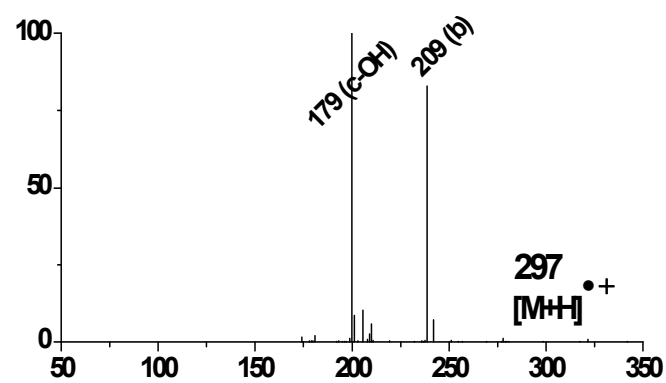

E. LC/MS ${ }^{2}$ of $\mathrm{m} / \mathrm{z} 449$

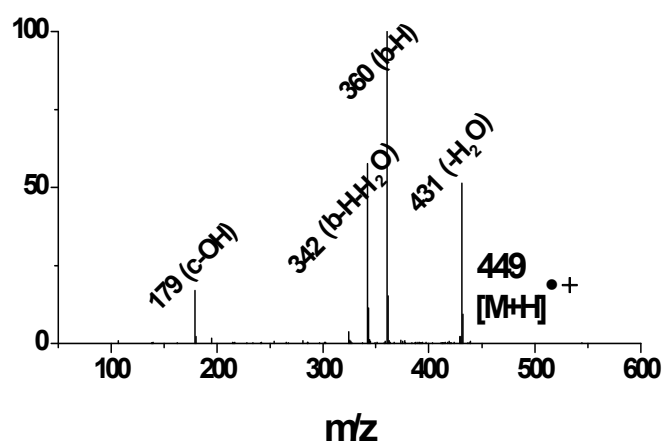

B. radicals from COX/DGLA system

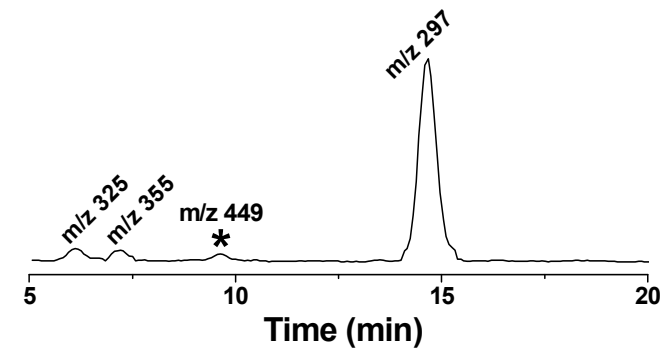

D. $L C / M S^{2}$ of $\mathrm{m} / \mathrm{z} 325$

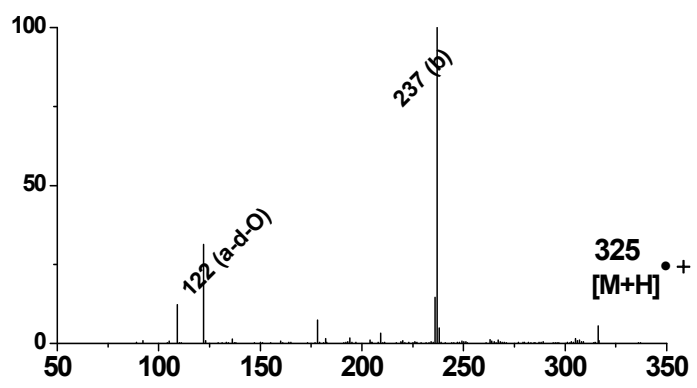

F. LC/MS ${ }^{2}$ of $\mathrm{m} / \mathrm{z} 355$

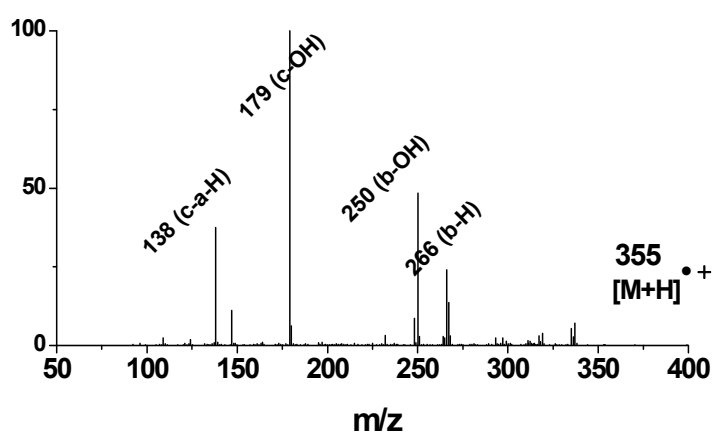


Figure 4. Profiles of reduced radical adducts in cellular PUFA peroxidation. (A) Profiles of the reduced common radical adduct $\mathrm{m} / \mathrm{z}$ 297; (B) Profiles of the reduced exclusive radical adduct $m / z 449$ in cells treated with AA; (C) Profiles of reduced exclusive radical adducts in cells treated with DGLA; (D) Profiles of reduced exclusive radical adducts in cells treated by DGLA with CP-24879. Note: the asterisked $m / z 449$ in COX/DGLA and COX/DGLA+CP-24879 systems actually comes from COX/AA peroxidation because DGLA can be converted into AA by $\Delta-5$ desaturase. When CP-24879, an inhibitor of $\Delta-5$ desaturase, was introduced into the COX/DGLA system, the exclusive AA-derived hydroxylamine $m / z 449$ was barely detected. N.D.: Not detected.

A. Common radical $\mathrm{m} / \mathrm{z} 297$

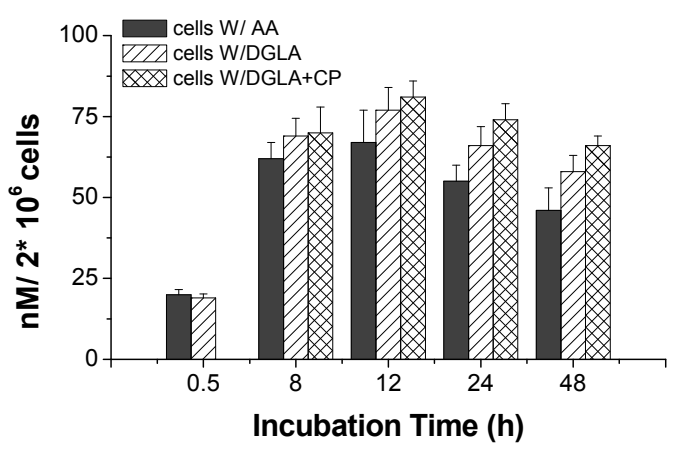

C. Exclusive radical product in COXIDGLA

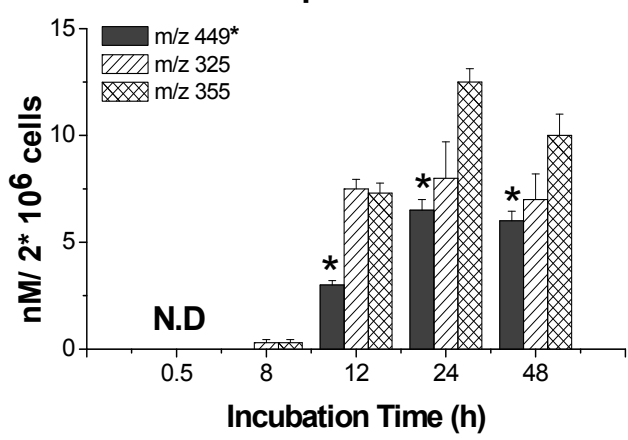

B. Exclusive radical $\mathrm{m} / \mathrm{z} 449$ in COXIAA

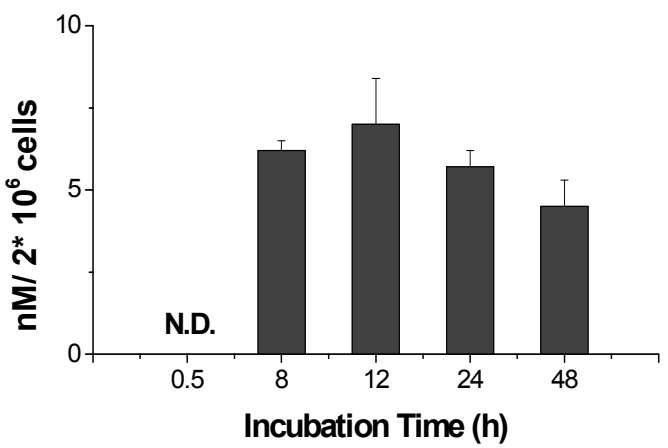

D. Exclusive radical product in COX/DGLA+CP

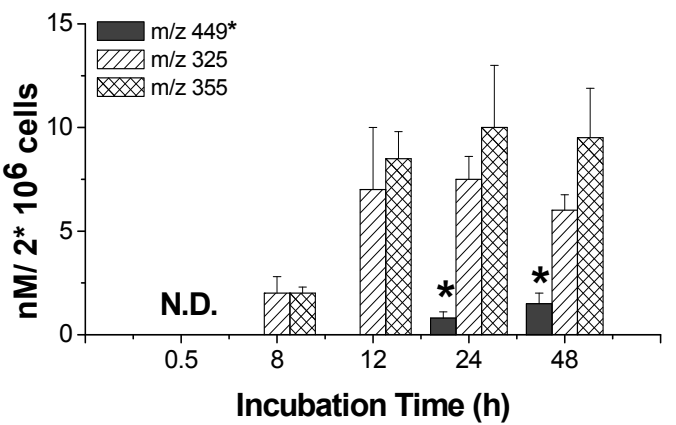

\section{Summary}

The refined combination of spin trapping with $\mathrm{LC} /(\mathrm{ESR}) / \mathrm{MS}$ not only optimizes the method's sensitivity and resolution, but also greatly improves the reliability of radical identification. Thus, it becomes a potent tool for the study of radical-mediated lipid peroxidation, as well as its association with PUFA's bioactivities. More important, the most recent ESR spin trapping and LC/MS technique with SPE has shown great advantages in the study of lipid peroxidation in cellular systems, particularly because it allows us to examine the radical production after a long incubation time and to assess its association with cancer cell growth. Thus, continued efforts to apply this advanced technique to exploring lipid peroxidation will definitely improve our knowledge of PUFAs' bioactivities in cancer biology and various inflammatory disorders, as well as the radical-based mechanisms behind it. 


\section{Acknowledgements}

This work was supported by NIH grants: K22ES-012978, R15CA140833, P20 RR015566; and supported by the U.S. Department of Agriculture under Agreement No: 59-0206-9-062 (a cooperative project with the U.S. Wheat \& Barley Scab Initiative).

\section{Conflict of Interest}

The authors declare no conflict of interest.

\section{References}

1. Das, U.N. Essential fatty acids: Biochemistry, physiology and pathology. Biotechnol. J. 2006, 1, 420-439.

2. Das, U.N. Essential fatty acids, lipid peroxidation and apoptosis. Prostaglandins Leukot. Essent. Fatty Acids 1999, 61, 157-163.

3. Sardesai, V.M. Nutritional role of polyunsaturated fatty acids. J. Nutr. Biochem. 1992, 3, 154-166.

4. Gardner, H.W. Oxygen radical chemistry of polyunsaturated fatty acids. Free Radic. Biol. Med. 1989, 7, 65-86.

5. Wagner, B.A.; Buettner, G.R.; Burns, C.P. Free radical-mediated lipid peroxidation in cells: Oxidizability is a function of cell lipid bis-allylic hydrogen content. Biochemistry 1994, 33, 4449-4453.

6. Girotti, A.W. Mechanisms of lipid peroxidation. Free Radic. Biol. Med. 1985, 1, 87-95.

7. Qian, S.Y.; Wang, H.P.; Schafer, F.Q.; Buettner, G.R. EPR detection of lipid-derived radicals from PUFA, LDL, and cell oxidations. Free Radic. Biol. Med. 2000, 29, 568-579.

8. Porter, N.A. Mechanisms for the autoxidation of polyunsaturated lipids. Accounts Chem. Res. 1986, 19, 262-268.

9. North, J.A.; Spector, A.A.; Buettner, G.R. Detection of lipid radicals by electron paramagnetic resonance spin trapping using intact cells enriched with polyunsaturated fatty acid. J. Biol. Chem. 1992, 267, 5743-5746.

10. Smith, W.L.; DeWitt, D.L.; Garavito, R.M. Cyclooxygenases: Structural, cellular, and molecular biology. Annu. Rev. Biochem. 2000, 69, 145-182.

11. Marnett, L.J.; Rowlinson, S.W.; Goodwin, D.C.; Kalgutkar, A.S.; Lanzo, C.A. Arachidonic acid oxygenation by COX-1 and COX-2. J. Biol. Chem. 1999, 274, 22903-22906.

12. Yamamoto, S. Mammalian lipoxygenases: Molecular structures and functions. Biochim. Biophys. Acta. 1992, 1128, 117-131.

13. Sano, H.; Kawahito, Y.; Wilder, R.L.; Hashiramoto, A.; Mukai, S.; Asai, K.; Kimura, S.; Kato, H.; Kondo, M.; Hla, T. Expression of cyclooxygenase-1 and -2 in human colorectal cancer. Cancer Res. 1995, 55, 3785-3789.

14. Wolff, H.; Saukkonen, K.; Anttila, S.; Antti, K.; Harri, V.; Ristimaki, A. Expression of cyclooxygenase-1 in human lung carcinoma. Cancer Res. 1998, 58, 4997-5001. 
15. Buskens, C.J.; van Rees, B.P.; Sivula, A.; Reitsma, J.B.; Haglund, C.; Bosma, P.J.; Offerhaus, G.J.A.; van Lanschot, J.J.B.; Ristimaki, A. Prognostic significance of elevated cyclooxygenase 2 expression in patients with adenocarcinoma of the esophagus. Gastroenterology 2002, 122, 1800-1807.

16. Sales, K.D.; Katz, A.A.; Davis, M.; Hinz, S.; Soeters, R.P.; Hofmeyr, M.D.; Millar, R.P.; Jabbour, H.N. Cyclooxygenase-2 expression and prostaglandin E2 synthesis are upregulated in carcinomas of the cervix: A possible autocrine/paracrine regulation of neoplastic cell function via EP2/EP4 receptor. J. Clin. Endocrinol. Metab. 2001, 86, 2243-2249.

17. Lee, L.M.; Pan, C.C.; Cheng, C.J.; Chi, C.W.; Liu, T.Y. Expression of cyclooxygenase-2 in prostate adenocarcinoma and benign prostatic hyperplasia. Anticancer Res. 2001, 21, 1291-1294.

18. Rouzer, C.A.; Marnett, L.J. Structural and functional differences between cyclooxygenases: Fatty acid oxygenases with a critical role in cell signaling. Biochem. Biophys. Res. Commun. 2005, 338, 34-44.

19. Pidgeon, G.P.; Lysaght, J.; Krishnamoorthy, S.; Reynolds, J.V.; O’Byrne, K.; Nie, D.; Honn, K.V. Lipoxygenase metabolism: Roles in tumor progression and survival. Cancer Metastasis Rev. 2007, 26, 503-524.

20. Vang, K.; Ziboh, V.A. 15-lipoxygenase metabolites of $\gamma$-linolenic acid/eicosapentaenoic acid suppress growth and arachidonic acid metabolism in human prostatic adenocarcinoma cells: Possible implications of dietary fatty acids. Prostaglandins Leukot. Essent. Fatty Acids 2005, 72, 363-372.

21. Das, U.N. Nutrients, essential fatty acids and prostaglandins interact to augment immune responses and prevent genetic damage and cancer. Nutrition 1989, 5, 106-110.

22. Porter, N.A.; Funk, M.O. Peroxy radical cyclization as a model for prostaglandin biosynthesis. J. Org. Chem. 1975, 40, 3614-3615.

23. Fan, Y.Y.; Ramos, K.S.; Chapkin, R.S. Cell cycle related inhibition of mouse vascular smooth muscle cell proliferation by prostaglandin E1: Relationship between prostaglandin E1 and intracellular cAMP levels. Prostaglandins Leukot. Essent. Fatty Acids 1996, 54, 101-107.

24. Gianetti, J.; de Caterina, M.; de Cristofaro, T.; Ungaro, B.; del Guercio, R.; de Caterina, R. Intravenous prostaglandin E1 reduces soluble vascular cell adhesion molecule-1 in peripheral arterial obstructive disease. Am. Heart J. 2001, 142, 733-739.

25. Pham, H.; Vang, K.; Ziboh, V.A. Dietary $\gamma$-linolenate attenuates tumor growth in a rodent model of prostatic adenocarcinoma via suppression of elevated generation of PGE2 and 5S-HETE. Prostaglandins Leukot. Essent. Fatty Acids 2006, 74, 271-282.

26. James, M.J.; Gibson, R.A.; Cleland, L.G. Dietary polyunsaturated fatty acids and inflammatory mediator production. Am. J. Clin. Nutr. 2000, 71, 343S-348S.

27. Fan, Y.Y.; Chapkin, R.S. Importance of dietary $\gamma$-linolenic acid in human health and nutrition. J. Nutr. 1998, 128, 1411-1414.

28. Takai, S.; Jin, D.; Kawashima, H.; Kimura, M.; Shiraishi-Tateishi, A.; Tanaka, T.; Kakutani, S.; Tanaka, K.; Kiso, Y.; Miyazaki, M. Anti-atherosclerotic effects of dihomo- $\gamma$-linolenic acid in ApoE-deficient mice. J. Atheroscler. Thromb. 2009, 16, 480-489. 
29. Menendez, J.A.; del Mar Barbacid, M.; Montero, S.; Sevilla, E.; Escrich, E.; Solanas, M.; Cortes-Funes, H.; Colomer, R. Effects of $\gamma$-linolenic acid and oleic acid on paclitaxel cytotoxicity in human breast cancer cells. Eur. J. Cancer 2001, 37, 402-413.

30. Henniga, B.; Lei, W.; Arzuaga, X.; Ghosha, D.D.; Saraswathia, V.; Toborekc, M. Linoleic acid induces proinflammatory events in vascular endothelial cells via activation of PI3K/Akt and ERK1/2 signaling. J. Nutr. Biochem. 2006, 17, 766-772.

31. Rose, D.P. Dietary fat, fatty acids and breast cancer. Breast Cancer 1997, 4, 7-16.

32. Tsuyoshi, T.; Igarashi, M.; Miyazawa, T. Conjugated eicosapentaenoic acid (EPA) inhibits transplanted tumor growth via membrane lipid peroxidation in nude mice. J. Nutr. 2004, 134, 1162-1166.

33. Wen, B.; Deutsch, E.; Opolon, P.; Auperin, A.; Frascognal, V.; Connault, E.; Bourhis, J. n-3 Polyunsaturated fatty acids decrease mucosal/epidermal reactions and enhance antitumour effect of ionising radiation with inhibition of tumour angiogenesis. Br. J. Cancer 2003, 89, 1102-1107.

34. Kuriki, K.; Hirose, K.; Wakai, K.; Matsuo, K.; Ito, H.; Suzuki, T.; Hiraki, A.; Saito, T.; Iwata, H.; Tatematsu, M.; et al. Breast cancer risk and erythrocyte compositions of n-3 highly unsaturated fatty acids in Japanese. Int. J. Cancer 2007, 121, 377-385.

35. Geelen, A.; Schouten, J.M.; Kamphuis, C.; Stam, B.E.; Burema, J.; Renkema, J.M.; Bakker, E.J.; van't Veer, P.; Kampman, E. Fish consumption, n-3 fatty acids, and colorectal cancer: A meta-analysis of prospective cohort studies. Am. J. Epidemiol. 2007, 166, 1116-1125.

36. Kokura, S.; Nakagawa, S.; Hara, T.; Boku, Y.; Naito, Y.; Yoshida, N.; Yoshikawa, T. Enhancement of lipid peroxidation and of the antitumor effect of hyperthermia upon combination with oral eicosapentaenoic acid. Cancer Lett. 2002, 185, 139-144.

37. Janzen, E.G.; Blackburn, B.J. Detection and identification of short-lived free radicals by electron spin resonance trapping techniques (spin trapping). Photolysis of organolead, -tin, and -mercury compounds. J. Am. Chem. Soc. 1969, 91, 4481-4490.

38. Janzen, E.G.; Gerlock, J.L. Substituent effects on the photochemistry and nitroxide radical formation of nitro aromatic compounds as studied by electron spin resonance spin-trapping techniques. J. Am. Chem. Soc. 1969, 91, 3108-3109.

39. Janzen, E.G. Spin trapping. Accounts Chem. Res. 1971, 4, 31-40.

40. Lagercrantz, C. Spin trapping of some short-lived radicals by the nitroxide method. J. Phys. Chem. 1971, 75, 3466-3475.

41. Dikalova, A.E.; Kadiiska, M.B.; Mason, R.P. An in vivo ESR spin-trapping study: Free radical generation in rats from formate intoxication-Role of the Fenton reaction. Proc. Natl. Acad. Sci. USA 2001, 98, 13549-13553.

42. Qian, S.Y.; Kadiiska, M.B.; Guo, Q.; Mason, R.P. A novel protocol to identify and quantify all spin trapped free radicals from in vitro/in vivo interaction of $\mathrm{HO}$ and DMSO: LC/ESR, LC/MS, and dual spin trapping combinations. Free Radic. Biol. Med. 2005, 38, 125-135.

43. Pazos, M.; Andersen, M.L.; Skibsted, L.H. Heme-mediated production of free radicals via preformed lipid hydroperoxide fragmentation. J. Agric. Food Chem. 2008, 56, 11478-11484.

44. Spulber, M.; Schlick, S. Using cyclodextrins to encapsulate oxygen-centered and carbon-centered radical adducts: The case of DMPO, PBN, and MNP spin traps. J. Phys. Chem. A 2010, 114, $6217-6225$. 
45. Guo, Q.; Qian, S.Y.; Mason, R.P. Separation and identification of DMPO adducts of oxygen-centered radicals formed from organic hydroperoxides by HPLC-ESR, ESI-MS and MS/MS. J. Am. Soc. Mass Spectrom. 2003, 14, 862-871.

46. Chamulitrat, W.; Takahashis, N.; Mason, R.P. Peroxyl, alkoxyl, and carbon-centered radical formation from organic hydroperoxides by chloroperoxidase. J. Biol. Chem. 1989, 264, 7889-7899.

47. Bose-Basu, B.; Derose, E.F.; Chen, Y.R.; Mason, R.P.; London, R.E. Protein NMR spin trapping with [methyl-13C3]-MNP: Application to the tyrosyl radical of equine myoglobinm. Free Radic. Biol. Med. 2001, 31, 383-390.

48. Qian, S.Y.; Chen, Y.R.; Deterding, L.J.; Fann, Y.C.; Chignell, C.F.; Tomer, K.B.; Mason, R.P. Identification of protein-derived tyrosyl radical in the reaction of cytochrome $\mathrm{c}$ and hydrogen peroxide: Characterization by ESR spin-trapping, HPLC and MS. Biochem. J. 2002, 363, 281-288.

49. Gunther, M.R.; Tschirret-Guth, R.A.; Witkowska, H.E.; Fann, Y.C.; Barr, D.P.; Ortiz De Montellano, P.R.; Mason, R.P. Site-specific spin trapping of tyrosine radicals in the oxidation of metmyoglobin by hydrogen peroxide. Biochem. J. 1998, 330, 1293-1299.

50. Barr, D.P.; Gunther, M.R.; Deterding, L.J.; Tomer, K.B.; Mason, R.P. ESR Spin-trapping of a protein-derived tyrosyl radical from the reaction of cytochrome $\mathrm{c}$ with hydrogen peroxide. J. Biol. Chem. 1996, 271, 15498-15503.

51. Lardinois, O.M.; Detweiler, C.D.; Tomer, K.B.; Mason, R.P.; Deterding, L.J. Identifying the site of spin-trapping in proteins by a combination of liquid chromatography, ELISA and off-line tandem mass spectrometry. Free Radic. Biol. Med. 2008, 44, 893-906.

52. Bhattacharjee, S.; Deterding, L.J.; Chatterjee, S.; Jiang, J.J.; Ehrenshaft, M.; Lardinois, O.; Ramirez, D.C.; Tomer, K.B.; Mason, R.P. Site-specific radical formation in DNA induced by $\mathrm{Cu}(\mathrm{II})-\mathrm{H} 2 \mathrm{O} 2$ oxidizing system, using ESR, immuno-spin trapping, LC-MS and MS/MS. Free Radic. Biol. Med. 2011, 50, 1536-1545.

53. Chatterjee, S.; Lardinois, O.; Bhattacharjee, S.; Tucker, J.; Corbett, J.; Deterding, L.; Ehrenshaft, M.; Bonini, M.G.; Mason, R.P. Oxidative stress induces protein and DNA radical formation in follicular dendritic cells of the germinal center and modulates its cell death patterns in late sepsis. Free Radic. Biol. Med. 2011, 50, 988-999.

54. Buettner, G.R.; Kelley, E.E.; Burns, C.P. Membrane lipid free radicals produced from L1210 murine leukemia cells by photofrin photosensitization: An electron paramagnetic resonance spin trapping study. Cancer Res. 1993, 53, 3670-3673.

55. Qian, S.Y.; Buettner, G.R. Iron and dioxygen chemistry is an important route to initiation of biological free radical oxidations: An electron paramagnetic resonance spin trapping study. Free Radic. Biol. Med. 1999, 26, 1447-1456.

56. Kadiiska, M.B.; Hanna, P.M.; Jordan, S.J.; Mason, R.P. Electron spin resonance evidence for free radical generation in copper-treated vitamin E- and selenium-deficient rats: In vivo spin-trapping investigation. Mol. Pharmacol. 1993, 44, 222-227.

57. Kadiiska, M.B.; Mason, R.P.; Dreher, K.L.; Costa, D.L.; Ghio, A.J. In vivo evidence of free radical formation in the rat lung after exposure to an emission source air pollution particle. Chem. Res. Toxicol. 1997, 10, 1104-1108. 
58. Kadiiska, M.B.; Morrow, J.D.; Awad, J.A.; Roberts, L.J.; Mason, R.P. Identification of free radical formation and F2- isoprostanes in vivo by acute $\mathrm{Cr}(\mathrm{VI})$ poisoning. Chem. Res. Toxicol. 1998, 11, 1516-1520.

59. Ghio, A.J.; Kadiiska, M.B.; Xiang, Q.H.; Mason, R.P. In vivo evidence of free radical formation after asbestos instillation: An ESR spin trapping investigation. Free Radic. Biol. Med. 1998, $24,11-17$.

60. Buettner, G.R. Spin trapping: EPR parameters of spin adducts. Free Radic. Biol. Med. 1987, 3, 259-303.

61. Iwahashi, H.; Parker, C.E.; Mason, R.P.; Tomer, K.B. Radical adducts of nitrosobenzene and 2-methyl-2-nitrosopropane with 12,13-epoxylinoleic acid radical, 12,13-epoxylinolenic acid radical and 14,15-epoxyarachidonic acid radical. Biochem. J. 1991, 276, 447-453.

62. Iwahashi, H.; Deterding, L.J.; Parker, C.E.; Mason, R.P.; Tomer, K.B. Identification of radical adducts formed in the reactions of unsaturated fatty acids with soybean lipoxygenase using continuous flow fast atom bombardment with tandem mass spectrometry. Free Radic. Res. 1996, 25, 255-274.

63. Qian, S.Y.; Tomer, K.B.; Yue, G.H.; Guo, Q.; Kadiiska, M.B.; Mason, R.P. Characterization of the initial carbon-centered pentadienyl radical and subsequent radicals in lipid peroxidation: Identification via on-line high performance liquid chromatography/electron spin resonance and mass spectrometry. Free Radic. Biol. Med. 2002, 33, 998-1009.

64. Qian, S.Y.; Yue, G.H.; Tomer, K.B.; Mason, R.P. Identification of all classes of spin trapped carbon-centered radicals in soybean lipoxygenase-dependent lipid peroxidation of $\omega-6$ polyunsaturated fatty acids via LC/ESR, LC/MS, and tandem MS. Free Radic. Biol. Med. 2003, 34, 1017-1028.

65. Qian, S.Y.; Guo, Q.; Mason, R.P. Identification of spin trapped carbon-centered radicals in soybean lipoxygenase-dependent peroxidation of $\omega-3$ polyunsaturated fatty acids by LC/ESR, LC/MS, and tandem MS. Free Radic. Biol. Med. 2003, 35, 33-44.

66. Yu, Q.; Shan, Z.; Ni, K.; Qian, S.Y. LC/ESR/MS study of spin trapped carbon-centered radicals formed from in vitro lipoxygenase-catalyzed peroxidation of $\gamma$-linolenic acid. Free Radic. Res. 2008, 42, 442-455.

67. Shan, Z.; Yu, Q.; Purwaha, P.; Guo, B.; Qian, S.Y. A combination study of spin-trapping, $\mathrm{LC} / \mathrm{ESR}$ and LC/MS on carbon-centred radicals formed from lipoxygenase-catalysed peroxidation of eicosapentaenoic acid. Free Radic. Res. 2008, 43, 1-15.

68. Purwaha, P.; Gu, Y.; Kelavkar, U.; Kang, J.X.; Law, B.; Wu, E.; Qian, S.Y. LC/ESR/MS study of pH-dependent radical generation from 15-LOX-catalyzed DPA peroxidation. Free Radic. Biol. Med. 2011, 51, 1461-1470.

69. Yu, Q.; Purwaha, P.; Ni, K.; Sun, C.; Mallik, S.; Qian, S.Y. Characterization of novel radicals from COX-catalyzed arachidonic acid peroxidation. Free Radic. Biol. Med. 2009, 47, 568-576.

70. Xiao, Y.; Gu, Y.; Purwaha, P.; Ni, K.; Law, B.; Mallik, S.; Qian, S.Y. Characterization of free radicals formed from COX-catalyzed DGLA peroxidation. Free Radic. Biol. Med. 2011, 50, 1163-1170.

71. Gu, Y.; Xu, Y.; Law, B.; Qian, S.Y. The first characterization of free radicals formed from cellular COX-catalyzed peroxidation. Free Radic. Biol. Med. 2012, in press. 
72. Miller, C.C.; McCreedy, C.A.; Jones, A.D.; Ziboh, V.A. Oxidative metabolism of dihomo-gammalinolenic acid by guinea pig epidermis: Evidence of generation of anti-inflammatory products. Prostaglandins 1988, 35, 917-938.

73. Gago-Dominguez, M.; Yuan, J.M.; Sun, C.L.; Lee, H.P.; Yu, M.C. Opposing effects of dietary n-3 and n-6 fatty acids on mammary carcinogenesis: The Singapore Chinese health study. Br. J. Cancer 2003, 89, 1686-1692.

74. Leitzmann, M.F.; Stampfer, M.J.; Michaud, D.S.; Augustsson, K.; Colditz, G.C.; Willett, W.C.; Giovannucci, E.L. Dietary intake of n-3 and n-6 fatty acids and the risk of prostate cancer. Am. J. Clin. Nutr. 2004, 80, 204-216.

75. Larsson, S.C.; Kumlin, M.; Ingelman-Sundberg, M.; Wolk, A. Dietary long-chain n-3 fatty acids for the prevention of cancer: A review of potential mechanisms. Am. J. Clin. Nutr. 2004, 79, 935-945.

(C) 2012 by the authors; licensee MDPI, Basel, Switzerland. This article is an open access article distributed under the terms and conditions of the Creative Commons Attribution license (http://creativecommons.org/licenses/by/3.0/). 